\title{
Cardiac Arrhythmias and Antiarrhythmic Drugs: An Autophagic Perspective
}

\author{
Joanne J. A. van Bavel, Marc A. Vos and Marcel A. G. van der Heyden* \\ Department of Medical Physiology, Division of Heart and Lungs, University Medical Center Utrecht, Utrecht, Netherlands
}

\section{OPEN ACCESS}

Edited by:

Carol Ann Remme,

University of Amsterdam, Netherlands

Reviewed by:

Thomas Hund

The Ohio State University,

United States

Craig Doupnik,

Morsani College of Medicine

University of South Florida,

United States

Rob Gourdie,

Medical University of South Carolina,

United States

*Correspondence:

Marcel A. G. van der Heyden

m.a.g.vanderheyden@umcutrecht.nl

Specialty section:

This article was submitted to

Cardiac Electrophysiology,

a section of the journal

Frontiers in Physiology

Received: 24 November 2017

Accepted: 07 February 2018

Published: 23 February 2018

Citation:

van Bavel JJA, Vos MA and van der

Heyden MAG (2018) Cardiac

Arrhythmias and Antiarrhythmic

Drugs: An Autophagic Perspective.

Front. Physiol. 9:127.

doi: 10.3389/fphys.2018.00127
Degradation of cellular material by lysosomes is known as autophagy, and its main function is to maintain cellular homeostasis for growth, proliferation and survival of the cell. In recent years, research has focused on the characterization of autophagy pathways. Targeting of autophagy mediators has been described predominantly in cancer treatment, but also in neurological and cardiovascular diseases. Although the number of studies is still limited, there are indications that activity of autophagy pathways increases under arrhythmic conditions. Moreover, an increasing number of antiarrhythmic and non-cardiac drugs are found to affect autophagy pathways. We, therefore, suggest that future work should recognize the largely unaddressed effects of antiarrhythmic agents and other classes of drugs on autophagy pathway activation and inhibition.

Keywords: autophagy, AMPK, antiarrhythmic drugs, arrhythmias, mTOR, heart

\section{INTRODUCTION}

Degradation of cellular material occurs mainly via two pathways: the ubiquitin-proteasome system (UPS) and the autophagy-lysosome pathway. The UPS targets mainly short-lived or misfolded proteins, whereas autophagy includes the degradation, digestion and recycling of autophagy substrates, by lysosomes ( $\mathrm{Li}$ et al., 2012). In healthy conditions, autophagy acts principally as a protective and control mechanism by maintaining cellular growth, proliferation, survival, and clearance of dying cells (Cremonese Filipi-Chiela et al., 2016). Over the last decade, an increasing amount of research has focused on autophagy and attention has been paid to the association between autophagy and cardiac diseases, including ischemia and hypertrophy. Thus far, a potential link between arrhythmic conditions and changes in autophagy activity has gained little attention, although the evidence for such interaction currently expands. There remains a need for increased research focus on the association between pro- and antiarrhythmic drugs and autophagy pathways in the heart. We review the link between cardiac autophagy and arrhythmic conditions, and the limitations regarding the effect of antiarrhythmic drugs on autophagy. Only a few years from now we can determine whether the current niche of arrhythmias and autophagy research will emerge in a mature field of investigation.

\section{AUTOPHAGY TYPES AND TARGETS}

Autophagy substrates (referred to as cellular material) include proteins, proteasomes, lysosomes, endoplasmic reticulum (ER), mitochondria, lipid droplets, polyribosomes, peroxisomes, bacteria, viruses and ruptured phagosomes. These substrates are targeted for degradation as long as they are freely accessible in the cytosol (Galluzzi et al., 2017). Three types of autophagic targeting are recognized (Figure 1A). Microautophagy is the least studied type of autophagy, which involves the direct uptake of soluble cellular substrates from the cytoplasm by invaginations 
in lysosomal membranes (Li et al., 2012). Macroautophagy, the best characterized variant of autophagy, is used synonymous with the term autophagy. It refers to both selective and nonselective capture of cellular components in double-membraned vesicles in the cytosol, and subsequent transport of the content to lysosomes (Feng et al., 2014). Chaperone-mediated autophagy (CMA) is a selective autophagic mechanism, which is mediated by the recognition of a peptide sequence in substrate proteins by chaperones, e.g. hsc70 (Cuervo and Wong, 2014). The substrate binds to lysosome-associated membrane protein 2A (LAMP-2A) and translocates into the lysosome for degradation. The main and most important function of the strictly organized process of autophagy is to maintain cellular homeostasis (Singh and Cuervo, 2011). Autophagy can act selectively, which includes the degradation of specific cargo selected by receptor proteins, and non-selectively by maintenance of intracellular nutrient supply with starvation as its main trigger (Svenning and Johansen, 2013). Besides small cellular components, selective autophagy can target specific cell components, e.g. mitochondria (mitophagy), ER (reticulophagy), ribosomes (ribophagy), lipids (lipophagy), and ion channels (channelophagy, as suggested by Klionsky et al., 2007; Kondratskyi et al., 2017). Autophagic processes are either continuously active (constitutive) or triggered (inducible). The primary stimulus of autophagy in yeast is nutrient withdrawal, whereas in mammals several stimuli can trigger autophagy, of which the most important are nutritional changes (e.g. starvation), organelle damage, hormonal regulation, infectious agents, hypoxia (such as in cardiac ischemia), and intracellular accumulation of toxic products (e.g. some antiarrhythmic drugs; Kudenchuk et al., 1984; Singh and Cuervo, 2011; Reggiori and Klionsky, 2013). The first reports on autophagic processes appeared in 1955. Christian de Duve coined the term "autophagy" in 1963, which was based on the discovery of self-eating lysosomes in rat hepatic cells (De Duve et al., 1955). The following decades, research focused on studying molecular autophagy mechanisms in yeast, which differ from autophagy processes in mammals (Matsuura et al., 1997; Reggiori and Klionsky, 2013). Furthermore, genetic screens revealed the existence of AuTophaGy-related (ATG) genes, of which the role in autophagy is associated to various processes in health and disease (Feng et al., 2014; Schneider and Cuervo, 2014). Recently,

\footnotetext{
Abbreviations: AF, atrial fibrillation; AMPK, AMP-activated protein kinase; AICAR, 5-aminoimidazole-4-carboxamide-1- $\beta$-D-ribofuranoside; Ara-A, adenine 9-beta-D-arabinofuranoside; ATG, AuTophaGy related; CMA, chaperonemediated autophagy; Cx43, connexin43; EPG5, ectopic P-granules autophagy protein 5; ER, endoplasmic reticulum; GABARAP, gamma-aminobutyric acid receptor-associated proteins; GSK3 $\beta$, glycogen synthase kinase $3 \beta$; HAT, histone acetyltransferase; HDAC, histone deacetylase; hERG, human ether-a-go-gorelated gene; hsc70, heat shock-cognate protein of $70 \mathrm{kDa}$; $\mathrm{IP}_{3}$, inositol 1,4,5-triphosphate; I/R, ischemia/reperfusion; LAMP-2A, lysosome-associated membrane protein 2A; LC3-II, microtubule-associated protein $1 \mathrm{~A} / 1 \mathrm{~B}$ chain 3 phosphatidylethanolamine conjugate; LTCC, L-type calcium channel; mTOR, mechanistic target of rapamycin; mTORC1, mTOR complex 1; $\mathrm{NAD}^{+}$, nicotinamide adenine dinucleotide; P-AMPK, phosphorylated AMPK; PI3KCIII, class III phosphatidylinositol 3-kinase; PKA, protein kinase A; RAP, rapid atrial pacing; SNARE, soluble NSF attachment protein receptor; TAC, transverse aortic constriction; TdP, torsade de pointes; TP53, transcription factor 53; ULK1/2, unc-51-like kinase 1 and 2; UPS, ubiquitin proteasome system.
}

the field of autophagy was honored by a Nobel Prize awarded to Yoshinori Ohsumi in 2016 (Levine and Klionsky, 2017).

\section{AUTOPHAGY-RELATED PROTEINS AND THEIR USE AS THERAPEUTICAL TARGETS}

ATG proteins are mainly described in macroautophagy because of its best-known machinery, and are illustrated in Figure 1B. Two important regulators of autophagy initiation are AMPactivated protein kinase (AMPK) and mechanistic target of rapamycin complex 1 (mTORC1). Active AMPK stimulates autophagy initiation, whereas mTORC1 inhibits autophagy (Kim et al., 2011). In autophagy stimulation, the ULK1/2-Atg13FIP200 complex becomes active, ATG proteins are recruited and a phagophore is formed (Xie et al., 2015). The class III phosphatidylinositol 3-kinase (PI3KCIII) complex (beclin1, VPS34, VPS15, and Atg14L) mediates nucleation of the phagophore (Baskaran et al., 2014). Different ubiquitin-like conjugation systems (Atg12-Atg5 and Atg8/LC3) are central in the next autophagic step; elongation of the phagophore, and proteins and lipids involved in autophagosome formation and maturation are recruited by the PI3KCIII complex (Feng et al., 2014; Xie et al., 2015). Beclin-1 is part of the PI3KCIII complex, and plays a key role in autophagosome formation and maturation (Xie et al., 2015). Mature autophagosomes move along microtubules and fuse with lysosomes in a process that involves gamma-aminobutyric acid receptorassociated proteins (GABARAP) and soluble NSF attachment protein receptor (SNARE) family proteins (Nair et al., 2011; Itakura et al., 2012). Autophagy's final step is degradation of the autophagolysosome cargo by different types of proteases (Kaminskyy and Zhivotovsky, 2012). Detailed overviews of the macroautophagy machinery are given by Feng et al. (2014) and Xie et al. (2015).

Inability to maintain cellular homeostasis due to defective autophagy associates with a variety of systemic diseases, such as cancer, neurodegeneration, liver disease and (cardio-) myopathies (Schneider and Cuervo, 2014). Distinct ATG proteins are considered as interesting targets for autophagy modulation (Figure 1B, Table 1), in which the field of cancer therapy progressed furthest (Mulcahy Levy et al., 2017). Rapamycin and its analogs (rapalogs) inhibit mTORC1 resulting in autophagy activation, and are used in certain cancer treatments (Li J. et al., 2014). Other recognized mTORC1 inhibitors are perhexiline (antianginal agent), niclosamide (used in treating worm infections), and rottlerin (natural product, known to open potassium channels) (Balgi et al., 2009). Activation of autophagy can also result from AMPK activators, such as commonly used antidiabetic agents metformin and phenformin, and AMP analog 5-aminoimidazole-4-carboxamide-1- $\beta$-D-ribofuranoside (AICAR) (Zhou et al., 2001; Yang et al., 2013; Ducommon et al., 2014). Common inhibitors of AMPK include adenine 9-beta$\mathrm{D}$-arabinofuranoside (Ara-A, or vidarabine) and compound C (Zhou et al., 2001; Pelletier et al., 2005). Antitumor drug wogonin can affect the next step in the autophagy pathway (phagophore nucleation) by targeting the beclin-1/PI3K complex, and thereby 
A

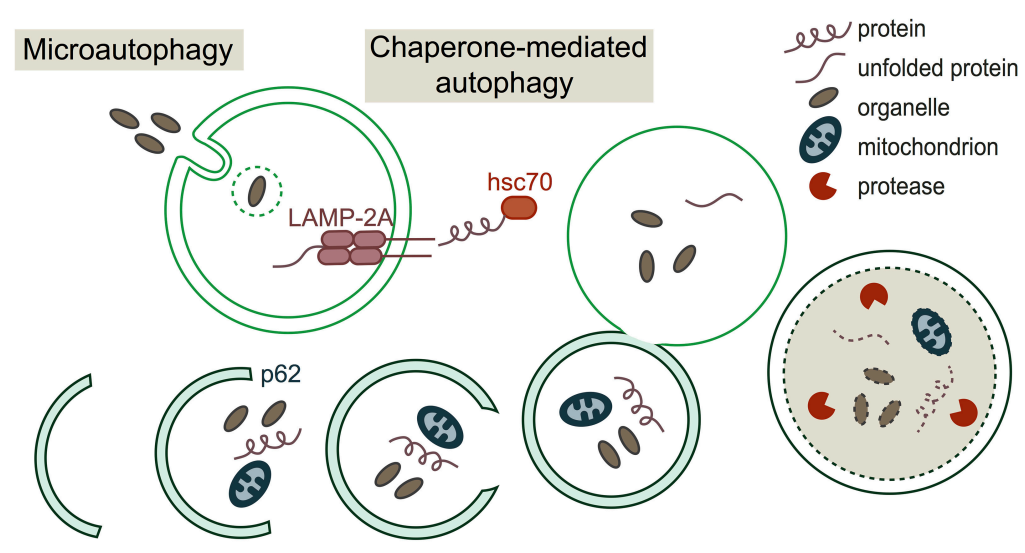

\section{Macroautophagy}

B

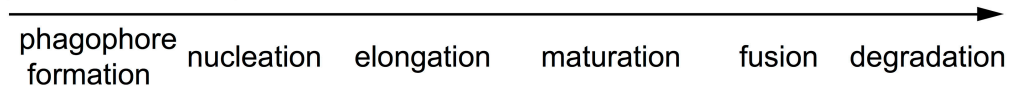

metformin

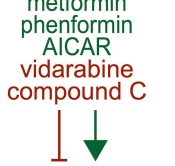
formation

class III

PI3K complex

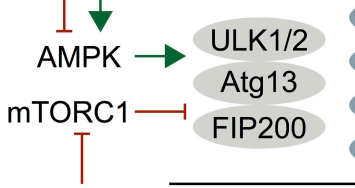

beclin-1

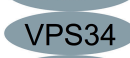

VPS15

Atg14L
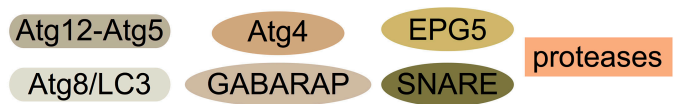

rapamycin
perhexiline
niclosamide
rottlerin
amiodarone

phagophore

formation

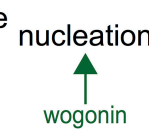

elongation



FIGURE 1 | Autophagy types, processes, molecular players and pharmacological regulators. (A) Schematic presentation of the three autophagy types.

Microautophagy refers to the direct uptake of soluble cellular substrates from the cytoplasm by invaginations in lysosomal membranes. Chaperone-mediated autophagy includes targeting of a specific motif in a substrate protein, translocation of the substrate to the lysosome by heat shock-cognate protein of $70 \mathrm{kDa}$ (hsc70), and translocation into the lysosome by lysosome-associated membrane protein 2A (LAMP-2A) on the lysosomal membrane. Macroautophagy starts with formation of a double-membraned phagophore, at which proteins and lipids are recruited by, among others, p62 (nucleation). Then, the phagophore elongates, matures, and the autophagosome fuses with a lysosome. (B) Overview of the mediators involved in macroautophagy and some of their stimulators/inhibitors (green and red respectively). Autophagy initiation occurs by activated AMPK, which phosphorylates the ULK1/2-Atg13-FIP200 complex. mTORC1 inhibits this complex. Once the autophagy pathway is activated, a phagophore is formed and the class III PI3K complex is responsible for nucleation. Two different conjugation systems are important for elongation of the phagophore (Atg12-Atg5 and Atg8/LC3). GABARAP and Atg4 are involved in autophagosome maturation, and fusion of the autophagosome with a lysosome is mediated by EPG5 and SNARE proteins. Finally, the cargo is degraded by proteases.

inducing autophagy in human pancreatic cancer cells ( $\mathrm{Li}$ et al., 2016). The antimalarial and anti-inflammatory agent chloroquine targets the last step in the autophagy pathway by inhibiting fusion of autophagosomes and lysosomes (Yoon et al., 2010). Although certain compounds seem to target autophagy pathways effectively, former mentioned compounds can act directly with a positive effect (e.g., tumor regression), as well as indirectly causing side effects.

\section{AUTOPHAGY IN THE HEART: SOME LESSONS FROM GENE DEFECTS}

Autophagy is important for maintenance of the highly organized cardiac structure, function and homeostasis. Nutrient insufficient conditions lead to the inactivation of mTORC1: rapamycin interacts with and inhibits mTORC1 activating unc-51-like kinase 1 and 2 (ULK1 and ULK2), leading to autophagy induction (Lavandero et al., 2013). Activation of sensitive nutrient sensor AMPK occurs when ATP/AMP levels decrease due to exercise, ischemia or lack of glucose, resulting in autophagy initiation (Hardie et al., 2012). Other important autophagy mediators in the cardiovascular system include inositol 1,4,5-triphosphate $\left(\mathrm{IP}_{3}\right)$, transcription factor 53 (TP53), cyclic AMP-dependent protein kinase A (PKA), histone acetyltransferases (HATs) and histone deacetylases (HDACs), glycogen synthase kinase $3 \beta$ (GSK3 $\beta$ ), nicotinamide adenine dinucleotide $\left(\mathrm{NAD}^{+}\right)$and microRNAs, which can initiate and inhibit autophagy, as reviewed by Lavandero et al. (2013). Impaired autophagy pathway signaling, due to ATG protein deficiency, may cause cardiac pathologies. 
Mice with Atg5 and Atg7 deficiency, ATG proteins involved in phagophore elongation, displayed dilated cardiomyopathy and contractile dysfunction, and accumulation of defective proteins and organelles, respectively (Komatsu et al., 2005; Nakai et al., 2007). Ectopic P-granules autophagy protein 5 (EPG5), important in translocation of autophagosomes to lysosomes, deficient individuals suffer from the Vici syndrome; a multisystem disorder with autophagy malfunction (Cullup et al., 2013). Cardiac symptoms, predominantly hypertrophy and left ventricular dilatation, are present in $90 \%$ of the Vici syndrome patients (Byrne et al., 2016). Deficiency of LAMP2 , required for the fusion of autophagosomes with endosomes and lysosomes (Endo et al., 2015), leads to Danon disease causing intellectual disability, skeletal myopathy and severe cardiomyopathy (D'souza et al., 2014). LAMP-2 deficient mice have a high mortality rate, show autophagosome accumulation in the pancreas, liver, kidney, skeletal muscle and heart, and possess cardiomyocytes filled with large vacuoles. The latter might be the cause of a reduced heart muscle contractility observed in these mice (Tanaka et al., 2000). Apart from the reductive, but instructive, ATG deficient models, most studies however focus on ischemia/reperfusion (I/R) and hypertrophy models to examine the role of cardiac autophagy (Lavandero et al., 2013).

\section{AUTOPHAGY IN CARDIAC ISCHEMIA/REPERFUSION AND HYPERTROPHY MODELS}

Both protective (clearance and removal of misfolded proteins and roles in energy homeostasis) and detrimental (massive digestion of cellular components and cross-talk to other forms of cell death) functions of autophagy have been presented in ischemic and hypertrophy models (Sciarretta et al., 2011). In the ischemic heart, upregulation of autophagy associates with a reduction in infarct size and apoptosis, and vice versa, suggested to work cardioprotective by maintaining energy levels (Sciarretta et al., 2014). In this situation, the drop in ATP levels during ischemia activates AMPK leading to an upregulation of autophagy activation (Takagi et al., 2007). In mice hearts however that underwent $I / R$, when oxygen and nutrient supply is impaired and subsequently restored, AMPK is inactivated, mTOR is upregulated, and beclin-1 is highly upregulated, suggesting an inhibition of autophagy (Matsui et al., 2007). Remarkably, these mice showed an increase in autophagosome levels and a decrease in apoptosis.

Cardiac hypertrophy is associated with an upregulation of autophagy. Weng et al. (2014) presented an increase in autophagic gene (Atg5 and Atg16) expression, and increased beclin-1 and microtubule-associated protein $1 \mathrm{~A} / 1 \mathrm{~B}$ chain 3 phosphatidylethanolamine conjugate (LC3-II) levels in transverse aortic constriction (TAC), to induce pressure overload, operated mice. Furthermore, AMPK induces autophagy in TAC operated hearts by regulating the mTORC1 pathway, leading to inhibition of cardiac hypertrophy and improved cardiac function (Li Y. et al., 2014). Cardiac-specific knockout of mTOR showed an impaired hypertrophic response and enhanced heart failure progression after TAC mediated pressure-overload in mice, suggesting detrimental effects when mTOR is lacking (Zhang et al., 2010). However, pharmacologic inhibition of mTOR indicates a cardiac protective effect: rapamycin treatment in TAC operated mice showed an inhibitory effect on cardiac hypertrophy development (McMullen et al., 2004). Moreover, treatment of rapamycin in cardiac transplant recipients resulted in reduced left ventricular mass and improved diastolic function (Raichlin et al., 2008). Altogether, current evidence states that regulation of autophagy levels is crucial in protecting cardiomyocytes under ischemic and hypertrophic conditions.

\section{INCREASED AUTOPHAGY ACTIVATION IN ARRHYTHMIC CONDITIONS}

Connexin43 ( $\mathrm{Cx} 43)$ proteins form gap junctions, which are responsible for the propagation of cardiac action potentials between cardiomyocytes. In the recent years, literature has been growing regarding the role of autophagy in degradation of $\mathrm{Cx} 43$ (Falk et al., 2014). A lowered expression of Cx43 was also linked to arrhythmias: among others, (Shu et al., 2017) showed a lowered $\mathrm{Cx} 43$ protein expression in a canine model with atrial fibrillation (AF) induced by rapid atrial pacing (RAP). It remains to be identified if a lowered $\mathrm{Cx} 43$ expression in arrhythmic conditions was mediated by autophagic degradation. As an indication of autophagy activation, levels of autophagy mediators have been examined in several arrhythmic conditions. A RAP canine model, vulnerable to AF, showed an increase in LC3B-II (LC3 family member) and phosphorylated AMPK (p-AMPK) protein levels (Yuan et al., 2014). Moreover, in the same study, it was presented that these autophagy mediators were increased in human patients suffering from AF. Furthermore, beclin-1 and LC3B-II expression levels were increased in I/R-injured fibrillated mouse hearts (Meyer et al., 2013). The increased levels of these autophagy mediators suggest increased autophagy activation in response to arrhythmias. Although the number of autophagic vacuoles was elevated in patients who underwent coronary artery bypass grafting with postoperative AF, decreased levels of LC3B-II levels were found in these patients (Garcia et al., 2012). A decrease in vesicle degradation and an impaired autophagic flow can clarify the elevated vesicle levels and the decreased LC3B-II levels, respectively (Garcia et al., 2012). These exciting findings, albeit just a few, appear to outpoint that autophagy pathways are becoming activated in arrhythmic conditions, and are therefore of interest as potential therapeutic targets. Nonetheless, the exact mechanistic relationship between autophagy and cardiac arrhythmias clearly remains to be elucidated.

\section{ANTIARRHYTHMIC DRUGS AFFECT AUTOPHAGY PATHWAYS}

Along with limited research into autophagy occurrence and regulation in arrhythmic conditions, only a few studies have thus far focused on the effect of antiarrhythmic drugs on autophagy activation and the results are interesting. Table 1 demonstrates the effect on autophagic regulation, the effective concentrations 
TABLE 1 | The effect of the discussed compounds on autophagy activation, their effective concentration on autophagy regulation, their therapeutic plasma concentrations, and their potential link to arrhythmic conditions.

\begin{tabular}{|c|c|c|c|c|c|}
\hline Compound & $\begin{array}{l}\text { Autophagic } \\
\text { activation }\end{array}$ & \multicolumn{2}{|c|}{ Concentrations } & \multirow{2}{*}{$\begin{array}{l}\text { Associated with } \\
\text { arrhythmias }^{\text {a }}\end{array}$} & \multirow{2}{*}{$\begin{array}{l}\text { References } \\
\begin{array}{l}\text { Zhou et al., 2001; Almilaji et al., } \\
2013\end{array}\end{array}$} \\
\hline AICAR & $\uparrow$ & $\begin{array}{l}\text { AMPK activation } \\
\text { Plasma levels }\end{array}$ & $\begin{array}{l}500 \mu \mathrm{M} \\
\text { not reported }\end{array}$ & & \\
\hline Amiodarone & $\uparrow$ & $\begin{array}{l}\text { mTORC1 inhibition } \\
\text { Plasma levels }\end{array}$ & $\begin{array}{l}>10 \mu \mathrm{M} \\
0.8-3.9 \mu \mathrm{M}\end{array}$ & $\begin{array}{l}+ \\
\text { QT prolongation }\end{array}$ & $\begin{array}{l}\text { Balgi et al., 2009; Tarapués } \\
\text { et al., 2014; Hrudikova } \\
\text { Vyskocilova et al., } 2017 .\end{array}$ \\
\hline Chloroquine & $\downarrow$ & $\begin{array}{l}\text { Autolysosome fusion } \downarrow \\
\text { Mean peak plasma level }\end{array}$ & $\begin{array}{l}120 \mu \mathrm{M} \\
0.4 \mu \mathrm{M}\end{array}$ & $\begin{array}{l}+ \\
\text { at high dose }\end{array}$ & $\begin{array}{l}\text { Walker et al., 1983; White, 2007; } \\
\text { Yoon et al., } 2010\end{array}$ \\
\hline Compound C & $\downarrow$ & $\begin{array}{l}\text { AMPK inhibition } \\
\text { Plasma levels }\end{array}$ & $\begin{array}{l}20 \mu \mathrm{M} \\
\text { not reported }\end{array}$ & $\begin{array}{l}\downarrow \text { (potentially) by } \\
\text { hERG activation }\end{array}$ & $\begin{array}{l}\text { Zhou et al., 2001; Almilaji et al., } \\
2013\end{array}$ \\
\hline Dronedarone & $\uparrow$ & $\begin{array}{l}\text { Autophagy activation } \\
\text { Steady-state plasma } \\
\text { levels }\end{array}$ & $\begin{array}{l}2 \mu \mathrm{M} \\
0.15-0.3 \mu \mathrm{M}\end{array}$ & $\begin{array}{l}+ \\
\text { QT prolongation }\end{array}$ & $\begin{array}{l}\text { Wadhani et al., 2006; Patel et al., } \\
\text { 2009; Piccoli et al., } 2011\end{array}$ \\
\hline Metformin & $\uparrow$ & $\begin{array}{l}\text { AMPK activation } \\
\text { Steady-state plasma } \\
\text { levels }\end{array}$ & $\begin{array}{l}>2 \mu \mathrm{M} \\
10-40 \mu \mathrm{M}\end{array}$ & $\begin{array}{l}\downarrow A F \text { in } \\
\text { DM patients }\end{array}$ & $\begin{array}{l}\text { Zhou et al., 2001; Chang et al., } \\
2014\end{array}$ \\
\hline Niclosamide & $\uparrow$ & $\begin{array}{l}\text { mTORC1 inhibition } \\
\text { Serum concentration } \\
\text { range }\end{array}$ & $\begin{array}{l}1 \mu \mathrm{M} \\
0.76- \\
18.32 \mu \mathrm{M}\end{array}$ & Not reported & $\begin{array}{l}\text { Andrews et al., 1982; Balgi et al., } \\
2009\end{array}$ \\
\hline Nifedipine & $\uparrow$ & $\begin{array}{l}\text { Autophagy activation } \\
\text { Mean peak plasma level }\end{array}$ & $\begin{array}{l}10 \mu \mathrm{M} \\
0.35 \mu \mathrm{M}\end{array}$ & $\begin{array}{l}\downarrow \\
\text { LTCC blocker }\end{array}$ & $\begin{array}{l}\text { Van Bortel et al., 1989; Redfern } \\
\text { et al., 2003; Pushparaj et al., } \\
2015\end{array}$ \\
\hline Paliperidone & $\uparrow$ & $\begin{array}{l}\text { Downstream effector } \\
\text { mTOR } \\
\text { Mean plasma level }\end{array}$ & $\begin{array}{l}\text { not reported } \\
84.4 \mathrm{nM}\end{array}$ & $\begin{array}{l}+ \\
\text { hERG inhibition }\end{array}$ & $\begin{array}{l}\text { Nazirizadeh et al., 2010; } \\
\text { Vigneault et al., 2011; Mas et al., } \\
2015\end{array}$ \\
\hline Pentamidine & $\uparrow$ & $\begin{array}{l}\text { Kir2.1 degradation } \\
\text { Plasma levels }\end{array}$ & $\begin{array}{l}5-10 \mu \mathrm{M} \\
0.5-2.4 \mu \mathrm{M}\end{array}$ & $\begin{array}{l}+ \\
\text { Risk for TdP }\end{array}$ & $\begin{array}{l}\text { Waalkes et al., 1970; Antoniou } \\
\text { and Gough, 2005; Nalos et al., } \\
2011\end{array}$ \\
\hline Perhexiline & $\uparrow$ & $\begin{array}{l}\text { mTORC1 inhibition } \\
\text { Serum concentration } \\
\text { range }\end{array}$ & $\begin{array}{l}1-10 \mu \mathrm{M} \\
0.8-3.8 \mu \mathrm{M}\end{array}$ & $\begin{array}{l}+ \\
\text { hERG inhibition }\end{array}$ & $\begin{array}{l}\text { Plicher et al., 1985; Walker et al., } \\
\text { 1999; Balgi et al., } 2009\end{array}$ \\
\hline Phenformin & $\uparrow$ & $\begin{array}{l}\text { AMPK activation } \\
\text { Plasma level }\end{array}$ & $\begin{array}{l}>0.3 \mathrm{mM} \\
0.27 \mu \mathrm{M}\end{array}$ & $\begin{array}{l}+ \\
\text { hERG inhibition }\end{array}$ & $\begin{array}{l}\text { Marchetti et al., 1987; Almilaji } \\
\text { et al., 2013; Vincent et al., } 2015\end{array}$ \\
\hline PI3K inhibitors ${ }^{b}$ & $\uparrow$ & $\begin{array}{l}\text { AMPK activation }{ }^{\mathrm{C}} \\
\text { Mean peak plasma level }\end{array}$ & $\begin{array}{l}5 \mu \mathrm{M} \\
3.6 \mu \mathrm{M}\end{array}$ & $\begin{array}{l}+ \\
\text { APD prolongation }\end{array}$ & $\begin{array}{l}\text { Fava et al., 2008; Yu et al., 2013; } \\
\text { Cohen et al., } 2017\end{array}$ \\
\hline Propranolol & $\downarrow$ & $\begin{array}{l}\text { Late block in autophagy } \\
\text { Plasma levels }\end{array}$ & $\begin{array}{l}10 \mu \mathrm{M} \\
20-428 \mu \mathrm{M}\end{array}$ & $\begin{array}{l}\downarrow \text { shorter QT } \\
\text { in LQT1 }\end{array}$ & $\begin{array}{l}\text { Castleden et al., 1975; Farah } \\
\text { et al., 2014; Ahn et al., } 2017\end{array}$ \\
\hline Ranolazine & $\uparrow$ & $\begin{array}{l}\text { Autophagy activation } \\
\text { Mean steady-state level }\end{array}$ & $\begin{array}{l}1 \mu \mathrm{M} \\
6 \mu \mathrm{M}\end{array}$ & $\begin{array}{l}\downarrow \\
\text { AF episodes }\end{array}$ & $\begin{array}{l}\text { CV Therapeutics Inc., 2007; } \\
\text { Huang et al., 2010; Guerra et al., } \\
2017\end{array}$ \\
\hline Rapamycin & $\uparrow$ & $\begin{array}{l}\text { mTORC1 inhibition } \\
\text { Target concentration } \\
\text { range }\end{array}$ & $\begin{array}{l}0.5-100 \mathrm{nM} \\
4-22 \mathrm{nM}\end{array}$ & $\begin{array}{l}+ \\
>28 n M\end{array}$ & $\begin{array}{l}\text { Stenton et al., 2005; Foster and } \\
\text { Toschi, 2009; Karakas et al., } \\
2016\end{array}$ \\
\hline Rottlerin & $\uparrow$ & $\begin{array}{l}\text { mTORC1 inhibition } \\
\text { Plasma levels }\end{array}$ & $\begin{array}{l}1-3 \mu \mathrm{M} \\
\text { not reported }\end{array}$ & $\begin{array}{l}+ \\
\text { APD shortening }\end{array}$ & Lu et al., 2008; Balgi et al., 2009 \\
\hline Verapamil & $\uparrow$ & $\begin{array}{l}\text { Autophagy activation } \\
\text { Mean peak plasma level }\end{array}$ & $\begin{array}{l}1 \mu \mathrm{M} \\
0.8 \mu \mathrm{M}\end{array}$ & $\begin{array}{l}\text { + LTCC and } \\
\text { hERG inhibition }\end{array}$ & $\begin{array}{l}\text { Frishman et al., 1982; Redfern } \\
\text { et al., 2003; Williams et al., } 2008\end{array}$ \\
\hline Vidarabine & $\downarrow$ & $\begin{array}{l}\text { AMPK inhibition } \\
\text { Mean peak plasma level }\end{array}$ & $\begin{array}{l}>0.5 \mathrm{mM} \\
3.7 \mu \mathrm{M}\end{array}$ & - & $\begin{array}{l}\text { Whitley et al., 1980; Pelletier } \\
\text { et al., 2005; Wada et al., } 2016\end{array}$ \\
\hline Wogonin & $\uparrow$ & $\begin{array}{l}\text { Beclin-1/PI3K activation } \\
\text { Plasma levels }\end{array}$ & $\begin{array}{l}40 \mu \mathrm{M} \\
\text { not reported }\end{array}$ & $\begin{array}{l}\downarrow \\
\text { in ischemic model }\end{array}$ & Lee et al., 2011; Li et al., 2016 \\
\hline
\end{tabular}


with arrhythmias (+), no association (-), preventive effect $(\downarrow)$ or "not reported."

${ }^{a}$ Arrhythmic associations tested in human, animal, or in vitro models.

${ }^{b}$ PI3K inhibitor examples are, as mentioned in the text, nilotinib, dasatinib, and sunitinib.

${ }^{c}$ Nilotinib concentration. 
affecting autophagy, the clinical effective concentrations, and a possible association with arrhythmias of the compounds discussed in this perspective. The effective concentrations of the compounds on autophagy regulation, although tested in vitro with limited concentration ranges, can be compared to drug plasma levels in patients. Overlapping concentrations indicate that a number of clinically used compounds are likely to influence authophagy regulation. Antiarrhythmic drugs are classified by the effect on the targets whose actions form the cardiac action potential. Class I drugs block $\mathrm{Na}^{+}$channels, class II drugs are adrenergic receptor antagonists, class III drugs are $\mathrm{K}^{+}$channel blockers, and the AV-node conduction is slowed down by class IV drugs usually by blockage of L-type calcium channels (LTCCs). The antiarrhythmic effects of $\mathrm{Na}^{+}$channel blocker ranolazine, initially developed as antianginal agent, are convincing (Gupta et al., 2015). Huang et al. (2010) showed induced autophagy activation after ranolazine treatment in HL1 cells and isolated rat cardiomyocytes. Commonly used betablocker propranolol is reported as autophagy inhibitor: increased LC3-II levels, autophagosome formation, and p62 (which degrades during autophagy stimulation) levels were measured in HepG2 cells, suggesting an inhibition of hepatic autophagy by propranolol at a later stage due to reduced degradation (Farah et al., 2014). Class III antiarrhythmic drug amiodarone inhibits mTORC1 leading to stimulation of the autophagy pathway, which was explored in vitro (Balgi et al., 2009). In another in vitro study, we indicated lysosomal impairment by amiodarone and its synthetic analog dronedarone, which resulted in increased inward rectifier potassium channel $\mathrm{K}_{\mathrm{ir}} 2.1$ expression and intracellular accumulation (Ji et al., 2017a). The well-known drawback of amiodarone is its high incidence of side effects, including thyroid toxicity, pulmonary toxicity, hepatic toxicity, neurological toxicity, which seem to be related to the lifetime cumulative dose of the drug (Santangeli et al., 2012). However, pharmacological activation of autophagy by amiodarone has been shown to improve liver regeneration after partial hepatectomy in mice (Lin et al., 2015). LTCC blocker nifedipine, used as arterial vasodilator, increases autophagic flow, as shown by increased presence of autophagosomes and LC3-II levels, and lower p62 levels in isolated rat cardiomyocytes (Pushparaj et al., 2015). LTCC blocker verapamil, used in treating angina and arrhythmias, increases autophagic flux, which was shown by elevated LC3-II levels in PC12 cells and in a series of human cell lines, in which the latter also included increased development of autophagic vacuoles (Williams et al., 2008; Kania et al., 2017). These studies, although limited in number, clearly represent the existing link between antiarrhythmic drugs and autophagy, and the direct outcomes can be both activation and inhibition of autophagy.

\section{NON-CARDIAC DRUGS CAN ACT PROARRHYTHMIC AND AFFECT AUTOPHAGY}

As well as antiarrhythmic compounds, non-cardiac drugs can have the tendency to act proarrhythmic, e.g. by prolonging the QT interval with an increased risk for Torsade de Pointes
(TdP) arrhythmias (Bossu et al., 2016), and they can affect the autophagic pathway. Many compounds with increased proarrhythmic risk are clinically used, or only reached phase I of clinical trials, to treat various disease areas. The former discussed drug chloroquine, which increases the lysosomal $\mathrm{pH}$ and thereby prevents the degradation of certain autophagy substrates, is reported as proarrhythmic. Accumulated levels of $\mathrm{K}_{\mathrm{ir}} 2.1$ were found intracellularly and $\mathrm{I}_{\mathrm{K} 1}$ densities increased due to chloroquine treatment (Jansen et al., 2008). From an autophagic perspective these results can be linked to the chloroquine-induced QT prolongation, conduction disturbances and cardiomyopathy at high doses, as reviewed by White (2007). The proarrhythmic effect of antiprotozoal drug pentamidine has been firstly reported in 1987 by the description of two case reports with occurrence of $\mathrm{TdP}$ arrhythmias after administration of pentamidine, which results have been confirmed later on (Wharton et al., 1987; Antoniou and Gough, 2005). We suggested a link between pentamidine and autophagy, in which pentamidine may induce lysosomal degradation of potassium channel $\mathrm{K}_{\mathrm{ir}} 2.1$ (Nalos et al., 2011). Pentamidine analogs have been, and still are, tested to finally develop efficient and specific $\mathrm{K}_{\mathrm{ir}} 2$.x ion-channel-carried inward rectifier current $\left(\mathrm{I}_{\mathrm{k} 1}\right)$ inhibitors for treating atrial fibrillation and short QT syndrome type 3 (Takanari et al., 2013; Ji et al., 2017b). Antipsychotic drug paliperidone, which inhibits human ether-a-go-go-related gene (hERG) $\mathrm{K}^{+}$channel, has also been characterized to increase the QT interval and increase the risk for TdP arrhythmia (Vigneault et al., 2011; Hagiwara et al., 2016). It may be assumed that it also affects autophagy, since mTOR was identified as a downstream effector of paliperidone-induced extrapyramidal symptoms (side effect of antipsychotics), as observed in a network analysis of gene expression (Mas et al., 2015). The role of autophagy in cancer has been characterized as paradoxical because of its pro-survival and pro-death outcomes (Helgason et al., 2013). A frequently altered pathway in cancer includes PI3K and its inhibitors seem to treat solid tumors and hematologic malignancies (Mayer and Arteaga, 2016). Nilotinib, dasatinib and sunitinib are examples of PI3K inhibitors, which are approved by the FDA to treat certain cancer types, and are shown to induce autophagy pathways in cancer cell models (Le et al., 2010; Yu et al., 2013; Wang et al., 2017). However, a recent study by Cohen et al. (2017), presented a prolongation of the action potential by former named PI3K inhibitors, and thereby clearly suggests that drug safety testing should be improved. The compounds discussed in this paragraph, either approved by the FDA or currently in clinical trials, seem to affect the autophagy pathway and cardiac action potential, while their original purpose is not to affect those. Causality however, needs to be demonstrated.

\section{CONCLUSION AND FUTURE PERSPECTIVES}

Autophagy regulation is crucial in basal and diseased conditions, and has been shown to act both protective and detrimental in cardiac disease models. Up to now, evidence has brought forward that autophagy activation changes in arrhythmic conditions of the heart. In addition, some antiarrhythmic drugs have been 
shown to affect autophagy pathways and this may associate with adverse effects. The direct effects and deciphering of the complex underlying mechanisms of antiarrhythmic drugs on autophagy mediation in the heart remain to be determined. Ion channels are crucial in maintaining a regular cardiac rhythm and some are also involved in autophagy regulation, as reviewed by Kondratskyi et al. (2017), indicating a possible direction of future research. Another research aim should be to understand the dependent role of remodeling on autophagy in cardiac arrhythmic conditions. Gene defect models and arrhythmia-induced models are promising in understanding the mechanistic relationship between autophagy and arrhythmias. We also suggest that future work should include the examination of autophagy effects in

\section{REFERENCES}

Ahn, J., Kim, H. J., Choi, J. I., Lee, K. N., Shim, J., Ahn, H. S., et al. (2017). Effectiveness of beta-blockers depending on the genotype of congenital long-QT syndrome: a meta-analysis. PLoS ONE 12:e0185680. doi: 10.1371/journal.pone.0185680

Almilaji, A., Munoz, C., Elvira, B., Fajol, A., Pakladok, T., Honisch, S., et al. (2013). AMP-activated protein kinase regulates hERG potassium channel. Eur. J. Physiol. 465, 1573-1582. doi: 10.1007/s00424-013-1299-8

Andrews, P., Thyssen, J., and Lorke, D. (1982). The biology and toxicology of molluscicides, bayluscide. Pharmacol. Ther. 19, 245-295. doi: 10.1016/0163-7258(82)90064-X

Antoniou, T., and Gough, K. A. (2005). Early-onset pentamidine-associated second-degree heart block and sinus bradycardia: case report and review of the literature. Pharmacotherapy 25, 899-903. doi: 10.1592/phco.2005.25.6.899

Balgi, A. D., Fonseca, B. D., Donohue, E., Tsang, T. C. F., Lajoie, P., Proud, C. G., et al. (2009). Screen for chemical modulators of autophagy reveals novel therapeutic inhibitors of mTORC1 signaling. PLoS ONE 4:e7124. doi: 10.1371/journal.pone.0007124

Baskaran, S., Carlson, L., Stjepanovic, G., Young, L. N., Kim, D. J., Grob, P., et al. (2014). Architecture and dynamics of the autophagic phosphatidylinositol 3-kinase complex. Elife 3:e05115. doi: 10.7554/eLife.05115

Bossu, A., Van der Heyden, M. A. G., De Boer, T. P., and Vos, M. A. (2016). A 2015 focus on preventing drug-induced arrhythmias. Expert Rev. Cardiovasc. Ther. 14, 245-253. doi: 10.1586/14779072.2016.1116940

Byrne, S., Dionisi-Vici, C., Smith, L., Gautel, M., and Jungbluth, H. (2016). Vici syndrome: a review. Orphanet J. Rare Dis. 11:21. doi: 10.1186/s13023-016-0399-x

Castleden, C. M., Kaye, C. M., and Parsons, R. L. (1975). The effect of age on plasma levels of propranolol and practolol in man. Br. J. Clin. Pharmacol. 2, 303-306.

Chang, S., Wu, L., Chiou, M., Liu, J., Yu, K., Kuo, C., et al. (2014). Association of metformin with lower atrial fibrillation risk among patients with type 2 diabetes mellitus: a population-based dynamic cohort and in vitro studies. Cardiovasc. Diabetol. 13:123. doi: 10.1186/014-0123-x

Cohen, I. S., Lin, R. Z., and Ballou, L. M. (2017). Acquired long QT syndrome and phosphoinositide 3-kinase. Trends Cardiovasc. Med. 27, 451-459. doi: 10.1016/j.tcm.2017.05.005

Cremonese Filipi-Chiela, E., Viegas, M. S., Paulo Thome, M., Buffon, A., Wink, M. R., and Lenz, G. (2016). Modulation of autophagy by calcium signalosome in human disease. Mol. Pharmacol. 90, 371-384. doi: 10.1124/mol.116.105171

Cuervo, A. M., and Wong, E. (2014). Chaperone-mediated autophagy: roles in disease and aging. Cell Res. 24, 92-104. doi: 10.1038/cr.2013.153

Cullup, T., Kho, A. L., Dionisi-Vici, C., Brandmeier, B., Smith, F., Urry, Z., et al. (2013). Recessive mutations in EPG5 cause Vici syndrome, a multisystem disorder with defective autophagy. Nat. Genet. 45, 83-87. doi: 10.1038/ng.2497

CV Therapeutics Inc. (2007). Data from: Ranexa (Ranolazine) Tablet, Film Coated, Extended Release. Available online at: https://dailymed.nlm.nih.gov/dailymed/ archives/fdaDrugInfo.cfm? archiveid $=5376$

De Duve, C., Pressman, B. C., Gianetto, R., Wattiaux, R., and Appelmans, F. (1955). Tissue fractionation studies. 6. Intracellular exploring the effectiveness of antiarrhythmic drugs. This may improve drug development to provide safer antiarrhythmic drugs by removal of autophagy pathway disturbances. Antiarrhythmic drugs may then not further worsen autophagy dysregulation in arrhythmic conditions. Beyond doubt, from an autophagic perspective; focus should increase on its regulation under arrhythmic conditions, and on the effects of its unknown targeting by antiarrhythmic compounds and other drugs.

\section{AUTHOR CONTRIBUTIONS}

All authors listed, have made substantial, direct and intellectual contribution to the work, and approved it for publication.

distribution patterns of enzymes in rat-liver tissue. Biochem. J. 60, 604-717.

D’souza, R. S., Levandowski, C., Slavov, D., Graw, S. L., Allen, L. A., Adler, E., et al. (2014). Danon disease: clinical features, evaluation, and management. Circ. Heart Fail. 7, 843-849. doi:10.1161/CIRCHEARTFAILURE.114. 001105

Ducommon, S., Ford, R. J., Bultot, L., Deak, M., Bertrand, L., Kemp, B. E., et al. (2014). Enhanced activation of cellular AMPK by dual-small molecule treatment: AICAR and A769662. Am. J. Physiol. Endocrinol. Metab. 306, 688-696. doi: 10.1152/ajpendo.00672.2013

Endo, Y., Furuta, A., and Nishino, I. (2015). Danon disease: a phenotypic expression of LAMP-2 deficiency. Acta Neurophatol. 129, 391-398. doi: 10.1007/s00401-015-1385-4

Falk, N. M., Kells, R. M., and Berthoud, V. M. (2014). Degradation of connexins and gap junctions. FEBS Lett. 588, 1221-1229. doi: 10.1016/j.febslet.2014.01.031

Farah, B. L., Sinha, R. A., Wu, Y., Singh, B. K., Zhou, J., Bay, B. H., et al. (2014). B-adrenergic agonist and antagonist regulation of autopahgy in HepG2 cells, primary mouse hepatocytes and mouse liver. PLoS ONE 9:e98155. doi: 10.1371/journal.pone.0098155

Fava, C., Kantarjian, H., Cortes, J., and Jabbour, E. (2008). Development and targeted use of nilotinib in chronic myeloid leukemia. Drug Des. Devel. Ther. 2, 233-243.

Feng, Y., He, D., Yao, Z., and Klionsky, D. J. (2014). The machinery of macroautophagy. Cell Res. 24, 24-41. doi: 10.1038/cr.2013.168

Foster, D. A., and Toschi, A. (2009). Targeting mTOR with rapamycin: one dose does not fit all. Cell Cycle 8, 1026-1029. doi: 10.4161/cc.8.7.8044

Frishman, W., Kirsten, E., Klein, M., Pine, M., Johnson, S. M., Hillis, L. D., et al. (1982). Clinical relevance of verapamil plasma levels in stable angina pectoris. Am. J. Cardiol. 50, 1180-1184. doi: 10.1016/0002-9149(82)90440-4

Galluzzi, L., Baehrecke, E. H., Ballabio, A., Boya, P., Bravo-San Pedro, J. M., Cecconi, F., et al. (2017). Molecular definitions of autophagy and related processes. EMBO J. 36, 1811-1836. doi: 10.15252/embj.201796697

Garcia, L., Verdejo, H. E., Kuzmicic, J., Zalaquett, R., Gonzalez, S., Lavandero, S., et al. (2012). Impaired cardiac autophagy in patients developing postoperative atrial fibrillation. J. Thorac. Cardiovasc. Surg. 143, 451-459. doi: 10.1016/j.jtcvs.2011.07.056

Guerra, F., Romandini, A., Barbarossa, A., Belardinelli, L., and Capucci, A. (2017). Ranolazine for rhythm control in atrial fibrillation: a systemic review and meta-analysis. Int. J. Cardiol. 15, 284-291. doi: 10.1016/j.ijcard.2016.11.103.

Gupta, T., Khera, S., Kolte, D., Aronow, W. S., and Iwai, S. (2015). Antiarrhythmic properties of ranolazine: a review of the current evidence. Int. J. Cardiol. 187, 66-74. doi: 10.1016/j.ijcard.2015.03.324

Hagiwara, M., Kambayashi, R., Aimoto, M., Nagasawam, Y., and Takahara, A. (2016). In vivo analysis of torsadogenic potential of an antipsychotic drug paliperidone using the acute atrioventricular block rabbit as a proarrhythmia model. J. Pharmacol. Sci. 132, 48-54. doi: 10.1016/j.jphs.2016.05.001

Hardie, D. G., Ross, F. A., and Hawly, S. A. (2012). AMPK: a nutrient and energy sensor that maintains energy homeostasis. Nat. Rev. Mol. Cell Biol. 13, 251-262. doi: $10.1038 / \mathrm{nrm} 3311$ 
Helgason, G. V., Holyoake, T. L., and Ryan, K. M. (2013). Role of autophagy in cancer prevention, development and therapy. Essays Biochem. 55, 133-151. doi: $10.1042 /$ bse 0550133

Hrudikova Vyskocilova, E., Grundmann, M., Duricova, J., and Kacirova, I. (2017). Therapeutic monitoring of amiodarone: pharmacokinetics and evaluation of the relationship between effect and dose/concentration. Biomed. Pap. Med. Fac. Univ. Palacky. Olomouc. Czech. Repub. 161, 134-143. doi: 10.5507/pb.2017.016

Huang, C., Yitzhaki, S., Perry, C. N., Liu, W., Giricz, Z., Mentzer, R. M., et al. (2010). Autophagy induced by ischemic preconditioning is essential for cardioprotection. J. Cardiacvasc. Transl. Res. 3, 365-373. doi: 10.1007/s12265-010-9189-3

Itakura, E., Kishi-Itakura, C., and Mizushima, N. (2012). The hairpin-type tailanchored SNARE syntaxin 17 targets to autophagosomes for fusion with endosomes/lysosomes. Cell 151, 1256-1269. doi: 10.1016/j.cell.2012.11.001

Jansen, J. A., De Boer, T. P., Wolswinkel, R., van Veen, T. A. B., Vos, M. A., van Rijen, H. V. M., et al. (2008). Lysosome mediated Kir2.1 breakdown directly influences inward rectifier current density. Biochem. Biophys. Res. Commun. 367, 686-692. doi: 10.1016/j.bbrc.2007.12.168

Ji, Y., Takanari, H., Qile, M., Nalos, L., Houtman, M. J. C., Romunde, F. L., et al. (2017a). Class III antiarhythmic drugs amiodarone and dronedarone impair Kir2.1 backward trafficking. J. Cell. Mol. Med. 21, 2514-2523. doi: $10.1111 /$ jcmm. 13172

Ji, Y., Veldhuis, M. G., Zandvoort, J., Romunde, F. L., Houtman, M. J. C., Duran, K., et al. (2017b). PA-6 inhibits inward rectifier currents carried by V93I and D172N gain-of-function Kir2.1 channels, but increases channel protein expression. J. Biomed. Sci. 24:44. doi: 10.1186/s12929-017-0352-x

Kaminskyy, V., and Zhivotovsky, B. (2012). Proteases in autophagy. Biochim. Biophys. Acta 1824, 44-50. doi: 10.1016/j.bbapap.2011.05.013

Kania, E., Pajak, B., O’Prey, J., Sierra Gonzalez, P., Litwiniuk, A., Urbanska, K., et al. (2017). Verapamil treatment induces cytoprotective autophagy by modulating cellular metabolism. FEBS J. 284, 1370-1387. doi: 10.1111/febs.14064

Karakas, N. M., Erdogan, I., Ozdemir, B., and Sezgin, A. (2016). Pain syndrome and ventricular arrhythmia induced by sirolimus and resolved by dosage adjustment in a child after heart transplant: a case report. Exp. Clin. Transplant. doi: 10.6002/ect.2015.0320. [Epub ahead of print].

Kim, J., Kundu, M., Viollet, B., and Guan, K. (2011). AMPK and mTOR regulate autophagy through direct phorphorylation of Ulk1. Nat. Cell Biol. 13, 132-141. doi: $10.1038 / \mathrm{ncb} 2152$

Klionsky, D. J., Cuervo, A. M., Dunn, W. A. Jr., Levine, B., Van der Klei, I. J., and Seglen, P. O. (2007). How shall I eat thee? Autophagy 3, 413-416. doi: 10.4161/auto.4377

Komatsu, M., Waguri, S., Ueno, T., Iwata, J., Murata, S., Tanida, I., et al. (2005). Impairment of starvation-induced and consitutive autophagy in Atg7-deficient mice. J. Cell Biol. 169, 425-434. doi: 10.1083/jcb.200412022

Kondratskyi, A., Kondratska, K., Skryma, R., Klionsky, D. J., and Prevarskaya, N. (2017). Ion channels in the regulation of autophagy. Autophagy 5,1-19. doi: $10.1080 / 15548627.2017 .1384887$

Kudenchuk, P. J., Pierson, D. J., Greene, H. L., Graham, E. L., Sears, G. K., and Trobaugh, G. B. (1984). Prospective evaluation of amiodarone pulmonary toxicity. Chest 86, 541-548. doi: 10.1378/chest.86.4.541

Lavandero, S., Tronscoso, R., Rothermel, B. A., Martinet, W., Sadoshima, J., and Hill, J. A. (2013). Cardiovascular autophagy: concepts, controversies, and perspectives. Autophagy 9, 1455-1466. doi: 10.4161/auto.25969

Le, X., Mao, W., Lu, Z., Carter, B., and Bast, R. C. (2010). Dasatinib induces autophagic cell death in human ovarian cancer. Cancer 116, 4980-4990. doi: $10.1002 / \mathrm{cncr} .25426$

Lee, Y. M., Cheng, P. Y., Chen, S. Y., Chung, M. T., and Sheu, J. R. (2011). Wogonin suppresses arrhythmias, inflammatory responses, and apoptosis induced by myocardial ischemia/reperfusion in rats. J. Cardiovasc. Pharmacol. 58, 133-142. doi: 10.1097/FJC.0b013e31821a5078

Levine, B., and Klionsky, D. J. (2017). Autophagy wins the 2016 nobel prize in physiology or medicine: breakthroughs in baker's yeast fuel advances in biomedical research. Proc. Natl. Acad. Sci. U.S.A. 114, 201-205. doi: $10.1073 /$ pnas.1619876114

Li, J., Kim, S. G., and Blenis, J. (2014). Rapamycin: one drug, many effects. Cell Metab. 19, 373-379. doi: 10.1016/j.cmet.2014.01.001

Li, S., Sun, S., Gao, J., and Sun, F. (2016). Wogonin induces Beclin$1 / \mathrm{PI} 3 \mathrm{~K}$ and reactive oxygen species-mediated autophagy in human pancreatic cancer cells. Oncol. Lett. 12, 5059-5067. doi: 10.3892/ol.201 6.5367

Li, W., Li, J., and Bao, J. (2012). Microautophagy: lesser-known self-eating. Cell. Mol. Life Sci. 69, 1125-1136. doi: 10.1007/s00018-011-0865-5

Li, Y., Chen, C., Yao, F., Su, Q., Liu, D., Xue, R., et al. (2014). AMPK inhibits cardiac hypertrophy by promoting autophagy via mTORC1. Arch. Biochem. Biophys. 558, 79-86. doi: 10.1016/j.abb.2014.06.023

Lin, C., Chen, Y., Lin, C., Chen, Y., Lo, G., Lee, P., et al. (2015). Amiodarone as an autophagy promotor reduces liver injury and enhances liver regeneration and survival in mice after partial hepatectomy. Sci. Rep. 5:15807. doi: $10.1038 /$ srep 15807

Lu, H. R., Vlaminckx, E., Hermans, A. N., Rohrbacher, J., Van Ammel, K., Towart, R., et al. (2008). Predicting drug-induced changes in QT interval and arrhythmias: QT-shortening drugs point to gaps in the ICHS7B guidelines. $\mathrm{Br}$. J. Pharmacol. 154, 1427-1438. doi: 10.1038/bjp.2008.191

Marchetti, P., Benci, L., Cecchetti, P., Giannarelli, R., Boni, C., Ciociaro, D., et al. (1987). Plasma biguanide levels are correlated with metabolic effects in diabetic patients. Clin. Pharmacol. Ther. 41, 450-454. doi: 10.1038/clpt.1987.55

Mas, S., Gasso, P., Parellada, E., Bernardo, M., and Lafuente, A. (2015). Network analysis of gene expression in peripheral blood identifies mTOR and NF$\mathrm{kB}$ pathways involved in antipsychotic-induced extrapyramidal symptoms. Pharmacogenomics J. 15, 452-460. doi: 10.1038/tpj.2014.84

Matsui, Y., Takagi, H., Qu, X., Abdellatif, M., Sakoda, H., Asano, T., et al. (2007). Distinct roles of autophagy in the heart during ischemia and reperfusion: roles of AMP-activated protein kinase and Beclin 1 in mediating autophagy. Circ. Res. 100, 914-922. doi: 10.1161/01.RES.0000261924. 76669.36

Matsuura, A., Tsukada, M., Wada, Y., and Ohsumi, Y. (1997). Apglp, a novel protein kinase required for the autophagic process in Saccharomyces cerevisiae. Gene 192, 245-250. doi: 10.1016/S0378-1119(97)00084-X

Mayer, I. A., and Arteaga, C. L. (2016). The PI3K/AKT pathway as a target for cancer treatment. Annu. Rev. Med. 67, 11-28. doi: 10.1146/annurev-med-062913-051343

McMullen, J. R., Sherwood, M. C., Tarnavski, O., Zhang, L., Dorfman, A. L., Shioi, T., et al. (2004). Inhibition of mTOR signaling with rapamycin regresses established cardiac hypertrophy induced pressure overload. Circulation 109, 3050-3055. doi: 10.1161/01

Meyer, G., Czompa, A., Reboul, C., Csepanyi, E., Czegledi, A., Bak, I., et al. (2013). The cellular autophagy markers beclin-1 and LC3B-II are increased during reperfusion in fibrillated mouse hearts. Curr. Pharm. Des. 19, 6912-6918. doi: $10.2174 / 138161281939131127122510$

Mulcahy Levy, J. M., Towers, C. G., and Thorburn, A. (2017). Targeting autophagy in cancer. Nat. Rev. Cancer 17, 528-542. doi: 10.1038/nrc.2017.53

Nair, U., Jotwani, A., Geng, J., Gammoh, N., Richerson, D., Yen, W., et al. (2011). SNARE proteins are required for macroautophagy. Cell 146, 290-302. doi: 10.1016/j.cell.2011.06.022

Nakai, A., Yamaguchi, O., Takeda, T., Higuchi, Y., Hikoso, S., Taniike, M., et al. (2007). The role of autophagy in the basal state and in response to hemodynamic stress. Nat. Med. 13, 619-624. doi: 10.1038/nm1574

Nalos, L., De Boer, T. P., Houtman, M. J. C., Rook, M. B., Vos, M. A., and Van der Heyden, M. A. G. (2011). Inhibition of lysosomal degradation rescues pentamidine-mediated decreases of K(ir)2.1 ion channel expression but not of K(v)11.1. Eur. J. Pharmacol. 652, 96-103. doi: 10.1016/j.ejphar.2010.10.093

Nazirizadeh, Y., Vogel, F., Bader, W., Haen, E., Pfuhlmann, B., Gründer, G., et al. (2010). Serum concentrations of paliperidone versus risperidone and clinical effects. Eur. J. Pharmacol. 66, 797-803. doi: 10.1007/s00228-010-0812-7

Patel, C., Yan, G. X., and Kowey, P. R. (2009). Dronedarone. Circulation 120, 636-644. doi: 10.1161/CIRCULATIONNAHA.109.858027

Pelletier, A., Joly, E., Prentki, M., and Coderre, L. (2005). Adenosine 5'monophosphate-activated protein kinase and p38 mitogen-activated protein kinase participate in the stimulation of glucose uptake by dinitrophenol in adult cardiomyocytes. Endocrinology 146, 2285-2294. doi: 10.1210/en.2004-1565

Piccoli, E., Nadai, M., Caretta, C. M., Bergonzini, V., Del Vecchio, C., Ha, H. R., et al. (2011). Amiodarone impairs trafficking through late endosomes inducing a Niemann-Pick C-like phenotype. Biochem. Pharmacol. 82, 1234-1249. doi: 10.1016/j.bcp.2011.07.090

Plicher, J., Cooper, J. D., Turnell, D. C., Matenga, J., Paul, R., and Lockhart, J. D. (1985). Investigations of long-term treatment with perhexiline maleate 
using therapeutic monitoring and electromyography. Ther. Drug. Monit. 7, 54-60.doi: 10.1097/00007691-198503000-00009

Pushparaj, C., Das, A., Purroy, R., Nager, M., Herreros, J., Pamplona, R., et al. (2015). Voltage-gated calcium channel blockers deregulate macroautophagy in cardiomyocytes. Int. J. Biochem. Cell Biol. 68, 166-175. doi: 10.1016/j.biocel.2015.09.010

Raichlin, E., Chandrasekaran, K., Kremers, W. K., Frantz, R. O., Clavelli, A. L., Pereira, N. L., et al. (2008). Sirolimus as primary immunosuppressant reduces left ventricular mass and improves diastolic function of the cardiac allograft. Transplantation 86, 1395-1400. doi: 10.1097/TP.0b013e318189049a

Redfern, W. S., Carlsson, L., Davis, A. S., Lynch, W. G., Machkenzie, I., Palethorpe, S., et al. (2003). Relationships between preclinical cardiac electrophysiology, clinical QT interval prolongation and torsade de pointes for a broad range of drugs: evidence for a provisional safety margin in drug development. Cardiovasc. Res. 58, 32-45. doi: 10.1016/S0008-6363(02)00846-5

Reggiori, F., and Klionsky, D. J. (2013). Autophagic processes in yeast: mechanism, machinery and regulation. Genetics 194, 341-361. doi: 10.1534/genetics.112.149013

Santangeli, P., Di Biase, L., Burkhardt, J. D., Bai, R., Mohanty, P., Pump, A., et al. (2012). Examining the safety of amiodarone. Expert Opin. Drug Saf. 11, 191-214. doi: 10.1517/14740338.2012.660915

Schneider, J. L., and Cuervo, A. M. (2014). Autophagy and human disease: emerging themes. Curr. Opin. Genet. Dev. 26, 16-23. doi: 10.1016/j.gde.2014.04.003

Sciarretta, S., Hariharan, N., Monden, Y., Zablocki, D., and Sadoshima, J. (2011). Is autophagy in response to ischemia and reperfusion protective or detrimental for the heart? Pediatr. Cardiol. 32, 275-281. doi: 10.1007/s00246-010-9855-x

Sciarretta, S., Yee, D., Shenoy, V., Nagarajan, N., and Sadoshima, J. (2014). The importance of autophagy in cardioprotection. High Blood Press. Cardiovasc. Prev. 21, 21-28. doi: 10.1007/s40292-013-0029-9

Shu, C., Huang, W., Zeng, Z., He, Y., Luo, B., Liu, H., et al. (2017). Connexin 43 is involved in the sympathetic atrial fibrillation in canine and canine atrial myocytes. Anatol. J. Cardiol. 18, 3-9. doi: 10.14744/AnatolJCardiol.2017.7602

Singh, R., and Cuervo, A. M. (2011). Autophagy in the cellular energetic balance. Cell Metab. 13, 495-504. doi: 10.1016/j.cmet.2011.04.004

Stenton, S. B., Partovi, N., and Ensom, M. H. H. (2005). Sirolimus. Clin. Pharmacokinet. 44, 769-786. doi: 10.2165/00003088-200544080-00001

Svenning, S., and Johansen, T. (2013). Selective autophagy. Essays Biochem. 55, 79-92. doi: 10.1042/bse 0550079

Takagi, H., Matsui, Y., Hirotani, S., Sakoda, H., Asano, T., and Sadoshima, J. (2007). AMPK mediates autophagy during myocardial ischemia in vivo. Autophagy 3 , 405-407. doi: 10.4161/auto.4281

Takanari, H., Nalos, L., Stary-Weinzinger, A., De Git, K. C. G., Varkevisser, R., Linder, T., et al. (2013). Efficient and specific cardiac Ik1 inhibition by a new pentamidine analogue. Cardiovasc. Res. 99, 203-214. doi: 10.1093/cvr/cvt103

Tanaka, Y., Guhde, G., Suter, A., Eskelinen, E., Hartmann, D., Lullmann-Rauch, R., et al. (2000). Accumulation of autophagic vacuoles and cardiomyopathy in LAMP-2-deficient mice. Nature 406, 902-906. doi: 10.1038/35022595

Tarapués, M., Cereza, G., Arellano, A. L., Montané, E., and Figueras, A. (2014). Serious QT interval prolongation with ranolazine and amiodarone. Int. J. Cardiol. 172, e60-e61. doi: 10.1016/j.ijcard.2013.12.061

Van Bortel, L., Böhm, R., Mooij, J., Schiffers, P., and Rahn, K. H. (1989). Total and free steady-state plasma levels and pharmacokinetics of nifedipine in patients with terminal renal failure. Eur. J. Clin. Pharmacol. 37, 185-189.

Vigneault, P., Kaddar, N., Bourgault, S., Caillier, B., Pilote, S., Patoine, D., et al. (2011). Prolongation of cardiac ventricular repolarization under paliperidone: how and how much? J. Cardiovasc. Pharmacol. 57, 690-695. doi: 10.1097/FJC.0b013e318217d941

Vincent, E. E., Coelho, P. P., Blagih, J., Griss, T., Viollet, B., and Jones, R. G. (2015). Differential effects of AMPK agonists on cell growth and metabolism. Oncogene 34, 3627-3639. doi: 10.1038/onc.2014.301

Waalkes, T. P., Denham, C., and DeVita, V. T. (1970). Pentamidine: clinical pharmacologic correlations in man and mice. Clin. Pharmacol. Ther. 11, 505-512. doi: $10.1002 /$ cpt1970114505

Wada, T., Nakamura, Y., Cao, X., Ohara, H., Izumi-Nakaseko, H., Nakazato, Y., et al. (2016). Antiviral drug vidarabine possessing cardiac type 5 adenylyl cyclase inhibitory property did not affect cardiohemodynamic or electrophysiological variables in the halothane-anesthetized dogs. J. Toxicol. Sci. 41, 115-122. doi: 10.2131/jts.41.115

Wadhani, N., Sarma, J. S. M., Singh, B. N., Radzik, D., and Gaud, C. (2006). Dosedependent effects of oral dronedarone on the circadian variation of RR and QT intervals in healthy subjects: implications for antiarrhythmic actions. $J$. Cardiovasc. Pharmacol. Ther. 11, 184-190. doi: 10.1177/1074248406290678

Walker, B. D., Valenzuela, S. M., Singleton, C. B., Tie, H., Bursill, J. A., Wyse, K. R., et al. (1999). Inhibition of HERG channels stably expressed in a mammalian cell line by the antianginal agent perhexiline maleate. Br. J. Pharmacol. 127, 243-251. doi: 10.1038/sj.bjp.0702502

Walker, O., Dawodu, A. H., Adeyokunnu, A. A., Salako, L. A., and Alvan, G. (1983). Plasma chloroquine and desethylchloroquine concentrations in children during and after chloroquine treatment for malaria. Br. J. Clin. Pharmac. 16, 701-705.

Wang, B., Lu, D., Xuan, M., and Hu, W. (2017). Antitumor effect of sunitinib in human prostate cancer cells functions via autophagy. Exp. Ther. Med. 13, 1285-1294. doi: 10.3892/etm.2017.4134

Weng, L., Zhang, W., Ye, Y., Yin, P., Yuan, J., Wang, X., et al. (2014). Aliskerin ameliorates pressure overload-induced heart hypertrophy and fibrosis in mice. Acta Pharmacol. Sin. 35, 1005-1014. doi: 10.1038/aps.2014.45

Wharton, J. M., Demopulos, P. A., and Goldschlager, N. (1987). Torsade de pointes during administration of pentamidine isethionate. Am. J. Med. 83, 571-576. doi: 10.1016/0002-9343(87)90774-1

White, N. J. (2007). Cardiotoxicity of antimalarial drugs. Lancet Infect. Dis. 7, 549-558. doi: 10.1016/S1473-3099(07)70187-1

Whitley, R. J., Tucker, B. C., Kinkel, A. W., Barton, N. H., Pass, R. F., Whelchel, J. D., et al. (1980). Pharmacology, tolerance, and antiviral activity of vidarabine monophosphate in humans. Antimicrob. Agents Chemother. 18, 709-715.

Williams, A., Sarkar, S., Cuddon, P., Ttofi, E. K., Saiki, S., Siddiqi, F. H., et al. (2008). Novel targets for Huntington's disease in an mTOR-independent autophagy pathway. Nat. Chem. Biol. 4, 295-305. doi: 10.1038/nchembio.79

Xie, Y., Kang, R., Sun, X., Zhong, M., Huang, J., Klionsky, D. J., et al. (2015). Posttranslational modification of autophagy-related proteins in macroautophagy. Autophagy 11, 28-45. doi: 10.4161/15548627.2014.984267

Yang, L., Sha, H., Davisson, R. L., and Qi, L. (2013). Phenformin activates the unfolded protein response in an AMP-activated protein kinase (AMPK)-dependent manner. J. Biol. Chem. 288, 13631-13638. doi: $10.1074 /$ jbc.M113.462762

Yoon, Y. H., Cho, K. S., Hwang, J. J., Lee, S., Choi, J. A., and Koh, J. (2010). Induction of lysosomal degradation, arrested autophagy, and cell death by chloroquine in cultured ARPE-19 cells. Invest. Ophthalmol. Vis. Sci. 51, 6030-6037. doi: 10.1167/iovs.10-5278

Yu, H., Lin, C., Tai, W., Liu, C., Shiau, C., and Chen, K. (2013). Nilotinib induces autophagy in hepatocellular carcinoma through AMPK activation. J. Biol. Chem. 288, 18249-18259. doi: 10.1074/jbc.M112.446385

Yuan, Y., Zhao, J., Yan, S., Wang, D., Zhang, S., Yun, F., et al. (2014). Autophagy: a potential novel mechanistic contributor to atrial fibrillation. Int. J. Cardiol. 172, 492-494. doi: 10.1016/j.ijcard.2014.01.027

Zhang, D., Contu, R., Latronico, M. V. G., Zhang, J. L., Rizzi, R., Catalucci, D., et al. (2010). MTORC1 regulates cardiac function and myocyte survival through $4 \mathrm{E}-$ BP1 inhibition in mice. J. Clin. Invest. 120, 2805-2816. doi: 10.1172/JCI43008

Zhou, G., Myers, R., Li, Y., Chen, Y., Shen, X., Fenyk-Melody, J., et al. (2001). Role of AMP-activated protein kinase in mechanism of metformin action. J. Clin. Invest. 108, 1167-1174. doi: 10.1172/JCI 13505

Conflict of Interest Statement: The authors declare that the research was conducted in the absence of any commercial or financial relationships that could be construed as a potential conflict of interest.

Copyright $\odot 2018$ van Bavel, Vos and van der Heyden. This is an open-access article distributed under the terms of the Creative Commons Attribution License (CC $B Y)$. The use, distribution or reproduction in other forums is permitted, provided the original author(s) and the copyright owner are credited and that the original publication in this journal is cited, in accordance with accepted academic practice. No use, distribution or reproduction is permitted which does not comply with these terms. 